\title{
The Value of Lead Logistics Services
}

\author{
Oliver Schneider ${ }^{1}$ and André Lindner ${ }^{2}$ \\ ${ }^{1}$ ETH Zurich, Center for Enterprise Sciences (BWI), 8092 Zurich, Switzerland \\ oschneider@ethz.ch \\ ${ }^{2}$ Kuehne + Nagel Management AG, 8834 Schindellegi, Switzerland \\ andre.lindner@kuehne-nagel.com
}

\begin{abstract}
Logistics Services are one of the most outsourced functions within a supply chain. This is due to easily transferrable know-how and traceable direct cost reductions, which directly impact the profit and loss statement. However, an effective management of materials and transportations on the supply and deliver side also carries indirect benefits by positively influencing the cash flow and the amount of capital locked up in inventories. Therefore, it also affects the balance sheet and the company's profitability. This paper describes an approach to make these effects transparent and traceable, by linking operational performance to the resulting changes in working capital. Having transparency on the direct and indirect effects fosters the service relationship and allows for new pricing concepts which carry advantages for both service provider and customer. The approach was developed in a collaborative action research project with a world leading provider of lead logistics services.
\end{abstract}

Keywords: Transportation Management, Enterprise Value, Productivity, Performance evaluation, Economic Value Added (EVA).

\section{Introduction}

Through the recent decades the idea of international division of labor and outsourcing has been pursued by nearly all companies with a manufacturing background. This has created multiple tier supply chains. Boosted by relatively low costs for transportation and various deregulations in international trade, such supply chains span significant distances and cover various time zones. Global supply chains have become the norm in business, resulting in increased lead times and decreased visibility.

In this context, Supply Chain Management (SCM) services have gained importance in recent years [1]. Not considered as a core competence, manufacturers outsource their supporting functions like the management of warehouses and logistical activities, and start to outsource tactical demand and supply planning.

SCM in its initial understanding tried to integrate information and material flows from the suppliers' suppliers to the customers' customers [2]. In practice, SCM in most cases has been understood as an execution activity running in isolation from sales and operations planning, creating artificial barriers and inefficiencies [3].

The emerging concept of lead logistics services (LLS) tries to cope with these barriers and inefficiencies. An example is the offering of the "supplier and inventory management (SIM)" service by a world leading LLS provider (LSP), which is a set of 
management services focusing on the dynamic alignment of demand with supply, including the setup and management of third-party logistics (3PL) providers in charge of the execution. It fulfills a given demand profile with a targeted level of inventory in compliance with customer defined constraints. SIM has to be understood as a layered service offering with three service modules, 1) "Execution Management", which is planning and coordination of transportation, 2) "Supply Logistics", dealing with the replenishment of the inbound warehouse, and 3) "End-to-End Demand and Supply Planning", which represents the Best Practice of "Integrated Demand and Supply Planning" of the SCOR-model.

SIM services support several activities at the OEM, namely the sales and operations planning, procurement, and distribution. Such a service is only possible because of recent advances in information technology (IT) [4]. A layered IT-architecture connects the different tiers within the supply chain.

\subsection{Objectives of the Paper}

This paper presents a method to quantify the value generated by SIM services from the perspective of the service consumer. Having a clear transparency on the value generated is important for several reasons. From the perspective of the service customer, this transparency is required before the decision on whether to buy this service or not, and after an outsourcing decision for an effective controlling of the LSP. From the perspective of the LSP this transparency is the basis for selling the service according to the customer's needs already from a qualitative perspective, and furthermore to define a price which is considered as fair by both service provider and service consumer [5]. The latter aspect is supported by a then possible new mode of logistics contracting. The basic principle is sharing - sharing of costs, revenues and risks, which is a core topic not only in recent supply chain research [6], but also in practice. Operational performance indicators and the resulting financial impact can be used for including incentives, which go beyond direct cost savings.

\subsection{Research Method}

Following Action Research (AR) principles [7], supplemented by the method of Systems Engineering [8], several contracts of a leading LSP were analyzed. A generic approach of displaying the different service relationships was developed, using the Supply Chain Operations Reference (SCOR-) model. A method to represent the influence of the supply chain operations on the different elements of working capital was developed and agreed upon. This concept is the basis to calculate a changed enterprise value caused by the LSP, in terms of the financial metric of the Economic Value Added (EVA). The concept was approved and implemented by the key actors of the LSP.

\section{Value Assessment of SIM Services}

Until now, there are only a few and very limited approaches to calculate the economic value which is generated by SCM services for the service consuming company [9]. They often do consider direct benefits (e.g. savings in transportation and administration cost, changes in inventory levels), but do not likewise consider monetary benefits 
resulting from higher availability, reliability, and shorter lead times. In order to understand these effects, it is important to know the relationship between SCM and financial management.

\subsection{Relationship of SCM and Financial Management}

The main goal of financial management is to create value for the stockholders through an effective use of capital, in terms of profitability, liquidity, and security [cf. e.g. 10]. From this overall objective, management tasks can be derived. On a daily basis, the working capital needs to be managed, in order to improve its utilization and reduce capital lockup. On an occasional basis, managers need to decide on stock and bond issues, dividends, and have to do capital budgeting for investments in fixed assets or cost reduction projects, in order to reduce operational risks and therefore improve the liquidity and the profitability of the supply chain [11].

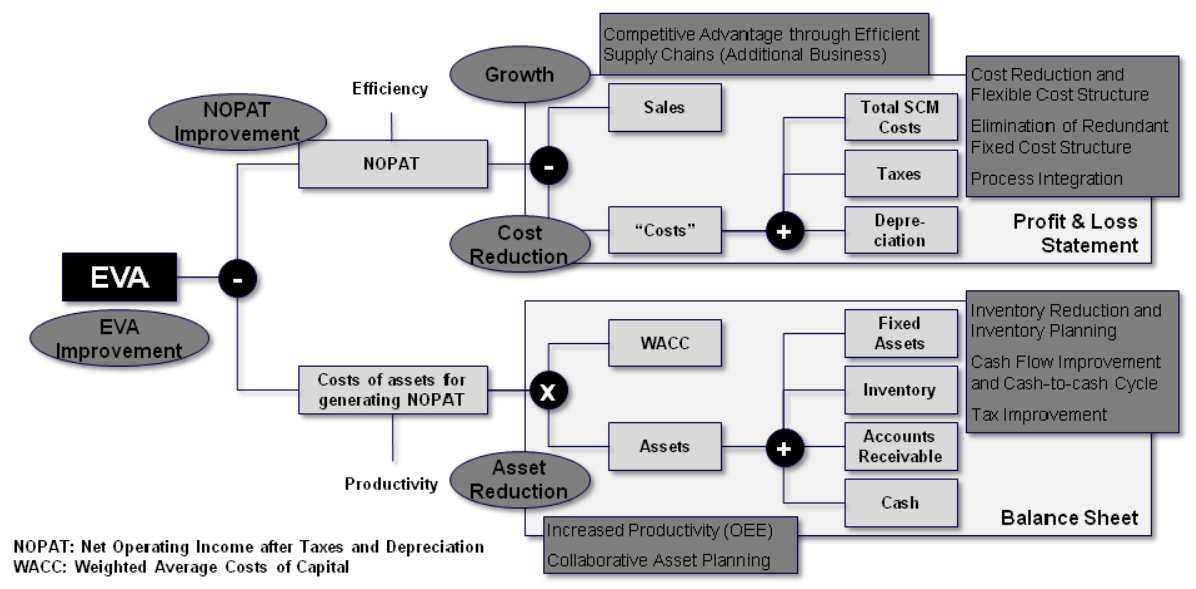

Fig. 1. Relationship of EVA and SCM improvement strategies

A well-established metric to express the generated value resulting from these management tasks is the Economic Value Added (EVA) [cf. e.g. 12]. The EVA is positive, i.e. value is generated, when an investment activity (in this case, a supply chain) leads to higher profit than the costs related to the utilization of the assets which are needed for performing the activity. The structure of EVA is shown in Fig. 1.

The EVA includes the Weighted Average Costs of Capital (WACC), which represent the investors' perspective in terms of financing costs (interest rates, which also take into account investment risks) and opportunity costs (alternative investments available on the market).

Important element of the EVA is the costs for financing the assets, which include the working capital as current assets. The working capital represents the capital which is "bound" in the operating business, meaning that it transforms its representation in the balance sheet by going through the different stages in a supply chain. 
Considering this, the EVA concept merges the aspect of operational performance in the form of sales and costs, and the financial perspective in the form of capital costs. This allows a continuous analysis of the enterprise value generated by its operating business [13]. There are three levers for improving the EVA, 1) sales, 2) costs (of goods sold), and 3) assets, for which financing costs occur. SCM offers improvement strategies and concepts which aim at exactly the three levers for improving the EVA. Therefore, effective SCM directly contributes to enterprise value [14].

\subsection{The Relationship of Operational Performance and Working Capital}

The core result of the presented research is displayed in Fig. 2. It represents a new way of linking operational supply chain performance to the elements of working capital and provides the basis for translating the performance into enterprise value. The underlying logic combines the use of the SCOR-model as an event-driven process reference model and the known flow of costs in a manufacturing company from an accounting perspective. This way the elements of working capital are clearly linked to the basic activities of a manufacturing company, providing the necessary transparency on supply chain performance from a financial perspective.

Source, Make, and Deliver represent the core execution activities of a manufacturing company. For the purpose of this paper, several events which are also described within lower SCOR levels are important. For producing its goods, a company needs raw material and components, which it sources from its suppliers. In a make-to-stock environment, a replenishment signal is sent to the supplier $\left(\mathrm{t}_{1}\right)$. After receiving this signal, the supplier has to prepare the delivery of the material. Assuming the use of the Incoterm code FCA (free carrier), the title of the material is transferred to the focal company $\left(t_{3}\right)$ at the moment the carrier picks up the delivery $\left(t_{2}\right)$. The pickup date is also the date of the invoice of the supplier, so the open invoice appears as accounts payable in the balance sheet of the focal company. Now having the title of the material, it also appears as inventory (in motion), evaluated to sourcing costs, including the costs of the transportation. At the time of delivery to the raw material inventory $\left(\mathrm{t}_{4}\right)$, it appears in the according position on the balance sheet. The payment terms with the supplier determine $t_{5}$, representing the time when the focal company pays the supplier and has a cash outflow. The invoice is closed and does not appear on the balance sheet anymore. $\mathrm{T}_{6}$ represents the time when the material is called off for production, then appearing not as raw material anymore, but as work in process. There value is added at every stage of production (with according expenses appearing in the accounts payable), until the assembly is finished and the products are stored in the finished goods inventory $\left(\mathrm{t}_{7}\right)$. After the customer order comes in $\left(\mathrm{t}_{8}\right)$, the loads are prepared and carriers selected, so that the products can be loaded $\mathrm{at}_{\mathrm{g}}$. Then they are considered as inventory in motion or in transit, when assuming Incoterm code DDU or DDP, (delivery duty unpaid/paid). From the moment on when the products are delivered and accepted by the customer $\left(t_{10}\right)$, and therefore the titles $\left(t_{11}\right)$ are transferred, the customer invoice is active. At this moment the products do not appear on the balance sheet of the focal company anymore, but the amount of the invoice appears on the accounts receivable. When the customer pays $\left(t_{12}\right)$, the amount disappears and the company has a cash inflow. 


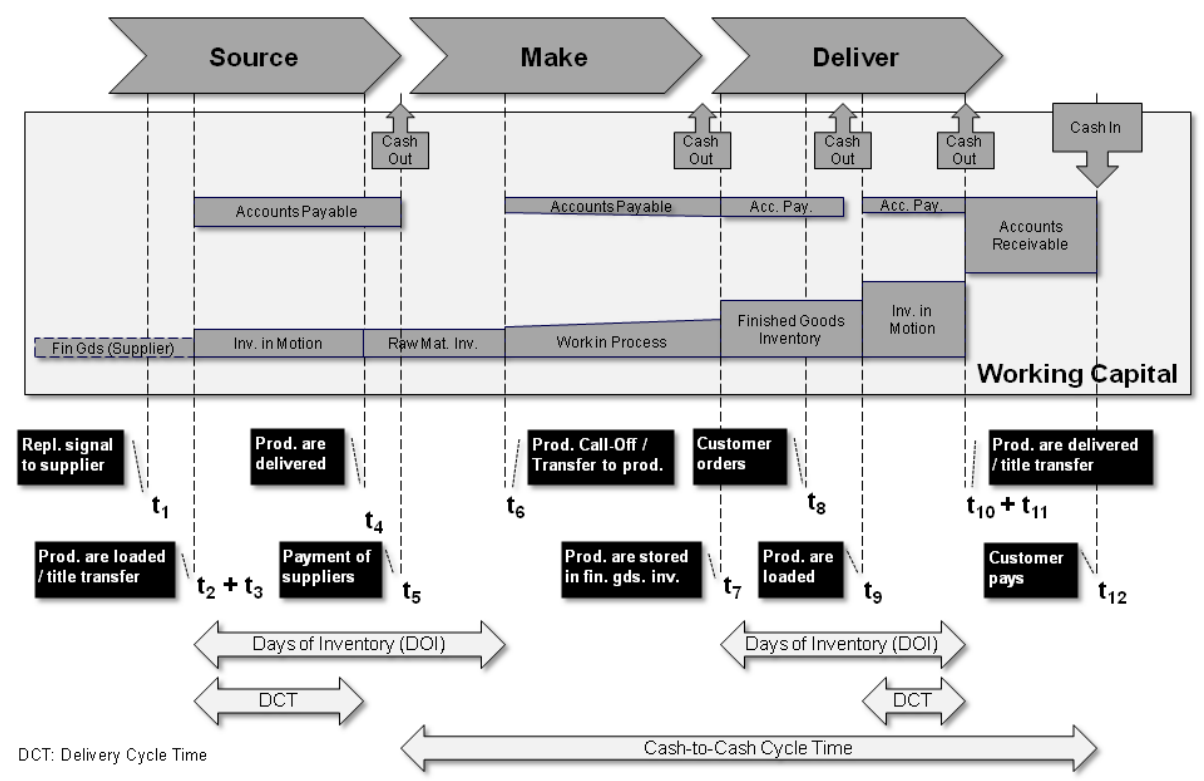

Fig. 2. SCOR level 1, supply chain events, key cycle time indicators, and the relationship to elements of working capital (make-to-stock environment)

As Fig. 2 displays, the time between the payment of suppliers and receiving the money from the customer represents the cash-to-cash cycle time. Additionally, the inbound and outbound delivery cycle times and the days of inventory play an important role. The shorter all the cycle times, the less capital is locked up in the form of inventories.

There is the need to explain the last statement in more detail. All material which is somehow inventory, either in motion, raw material, in process, or finished goods, appears on the balance sheet evaluated to actual total costs. This has two important consequences. First, in case costs per unit are lowered, the evaluation is decreased at the same amount. Second, considering that the balance sheet is a snapshot of the company's asset and capital situation at a given time, there is material in the whole pipeline, which all appears as inventory in the according stage. The shorter the pipeline, the less material adds up in the position of inventory. In Fig. 2, the height of the inventory rectangles represents the evaluation of the material at the particular stage. The widths represent the duration of time (or cycle time) the material remains within the particular stage, and therefore the length of the pipe at a given point of time. The area of the rectangles is the value of the particular element of working capital which appears on the balance sheet. So both cost and cycle time reductions reduce the amount of bound capital within a company.

This relationship provides the basis to show the influence of SIM services on the financial performance of the manufacturer. In the following, an exemplary scenario is given. 


\subsection{Assessing the Economic Value of SIM Services}

In this paper, the basic service module of Execution Management is taken as an example to describe the value proposition and according assessment of generated enterprise value.

SIM Execution Management services take over the planning and management of the material goods flows outside the production. Organizational barriers are removed by integrating separate IT-systems into a single planning solution. Based on the integrated plans, the transportation on the supply and deliver side is managed. This reduces costs and management effort, especially by limiting exception management ("fire-fighting") of transportation and replenishment operations.

In the framework of the AR project with the LSP, a comprehensive list of qualitative SIM service benefits was developed. The benefits were represented in the SCOR language, and a realistic example scenario was developed. It deals with the shipping of high-end pharmaceutical equipment from Europe to the USA. One pallet is worth 1 $\mathrm{M} €$ (Costs of Goods Sold, i.e. COGS, plus distribution costs), and 1000 pallets are shipped in a year. The costs for shipping every pallet from Europe to the USA with the current carriers are $10 \mathrm{k} €$, and pre-, main-, and post-transport take 15 days. During a financial year the shipping costs sum up to $10 \mathrm{M} €$.

After the engagement of the LSP, the situation changes as follows. Through a reduction of the number of carriers and a following renegotiation, supplemented by a more efficient use of planners' time, the shipping costs per pallet can be reduced to 8 $\mathrm{k} €$. The faster planning and carrier selection, as well as the selection of better carriers and routes, reduces the outbound delivery cycle time to only 10 days.

Based on the logic of Fig. 2, the financial effects are as follows. Assuming a requirement to ship every day, 2.8 pallets are sent out every day with 42 pallets in transit at the same time in the as-is scenario. The material in transit therefore is worth 42.420 M€, (42 M€ + $420 \mathrm{k} €$ transportation costs). Because of the reduced shipping costs in the improved scenario, less costs need to be attributed to the COGS. Therefore, one pallet in transit is now evaluated with $1.008 \mathrm{M} €$ instead of $1.010 \mathrm{M€}$. Because of the faster delivery cycle time, now only 28 pallets are in transit at the same time, in total evaluated with 28.224 M€ (releasing 14.196 M€ of capital lockup). Because of the reduced shipping costs, the service customer has to pay less to the 3PL, reducing the accounts payable by $20 \%$ (from $840 \mathrm{k} €$ to $672 \mathrm{k} €$, assuming payment terms of 30d, resulting in open invoices for 84 shipped pallets in one month).

In total, 14.196 M€ capital is released, when compared to the initial situation, and the Earnings Before Interest and Taxes (EBIT) are increased by $2 \mathrm{M} €$ due to the higher gross profit margin caused by the lower transportation costs. In the logic of the EVA, the amount of released capital can be evaluated against the costs for capital, by using the Weighted Average Costs for Capital (WACC) of the company. Because the accounts payable are part of financing a company's business (as short-term credit from the suppliers), the amount of $168 \mathrm{k} €$ needs to be deducted from the released capital, because the case company needs to finance this amount through other sources. In the described example and an assumed WACC of $10 \%$, the saved costs of capital therefore are $1.403 \mathrm{M} €$. Using the EVA calculation logic, this amount can be added to the 2 M€ EBIT improvement. Neglecting probable changes in safety stock levels due to the shorter lead times and changes in tax expenses, the resulting EVA is 3.403 M€. 


\section{Summary, Practical Implications and Outlook}

It was shown, that for calculating the financial impact of transportation management services in the more comprehensive manner of the EVA "classic" indicators as costs and cycle time already qualify. Within the described AR project, the other service modules were examined as well. It was identified that two other key performance characteristics come into play, when providing an even more comprehensive lead logistics solution, namely the reliability in the form of the key metric "Perfect Order Fulfillment", and the "Ability to Commit" in the form of lost sales. A detailed description of these relationships exceeds the limited frame of this article.

The transparency on the generated financial impact provides benefits for both the service provider and service consumer. The latter is supported in doing his make-orbuy decision, by making realistic assumptions on the prospected changes in working capital, and later in controlling the effectiveness of the service provider based on actual performance. The service provider can use information on prospected changes in the working capital of the potential customer as a sales argument, displaying the differentiation value.

The yearly control of the financial impact can be used as an essential element for pricing the service, for instance by implementing gain and risk sharing elements. When applied in an appropriate manner, such service pricing results in the strong incentive for both sides to continuously improve operations, in order to benefit more and more from the generated value.

The proposed concept also carries some limitations. For instance, some changes will be required, in order to implement the service as described. This applies to the organization itself, and the employed IT-infrastructure. Therefore aspects of Change Management must be considered, supplemented by a strong focus on information flows and the according master data within the IT system. A strong requirement in this regard is a high level of trust between the partners.

Moreover, an important requirement for the method is a clear filtering of effects of changes at the customer which are not caused by the service provider, for instance, changes in shipping volumes, the product characteristics, or regions in scope. The experiences of the LSP with gain share contracts show that it is necessary to agree on a clear scope of the influence area and required basic filtering aspects already beforehand. This results in a regular calculation and negotiation effort, which is not to be underestimated. However, this additional effort is considered as worthwhile, because the awareness of the quality and value contribution of collaboration is kept at a constant high level, which builds trust.

The project which developed the described approach focused on assessing the financial impact of lead logistics services. However, it was identified that the concept should also qualify for other types of activities, i.e. basically with any activity related to planning and execution of material and information flows within a supply chain. Therefore the paper provides the basis for further research in the field of SCM and Lean Management, which wants to show a comprehensive and holistic picture on the value of internal improvement projects or make-or-buy decisions. 


\section{References}

1. Klaus, P., Kille, C.: Die Top 100 der Logistik: Marktgrößen, Marktsegmente und Marktführer in der Logistikdienstleistungswirtschaft (4. Aufl.). Dt. Verkehrs-Verl., Hamburg (2006)

2. Schönsleben, P.: Integral logistics management: Operations and supply chain management in comprehensive value-added networks, 3rd edn. Auerbach Publications, Boca Raton (2007)

3. Sandberg, E.: Logistics collaboration in supply chains: practice vs. theory. Int. J. Log. Man. 18(2), 274-293 (2007)

4. Bauknight, D.N.: The Supply Chain's Future in the e-Economy...: And Why Many May Never See It. Supply Chain Management Review 4(1), 28-35 (2000)

5. Schneider, O., Lange, I., Nitu, B.: Enabling Industrial Service Providers to offer Comprehensive Service Contracts. In: 13th International Conference on Concurrent Enterprising (ICE), Sophia-Antipolis, pp. 295-304 (2007)

6. Melnyk, S.A., Lummus, R.R., Vokurka, R.J., Burns, L.J., Sandor, J.: Mapping the future of supply chain management: a Delphi study. Int. J. Prod. Res. 47(16), 4629-4653 (2009)

7. Greenwood, D.J., Levin, M.: Introduction to Action Research: Social research for social change. Sage Publ., Thousand Oaks (1998)

8. Haberfellner, R., Daenzer, W.F.: Systems Engineering: Methodik und Praxis (11. durchgesehene Auflage). Verlag Industrielle Organisation, Zürich (2002)

9. Sennheiser, A., Schnetzler, M.: Wertorientiertes Supply Chain Management. Springer, Berlin (2008)

10. Stührenberg, L., Streich, D., Henke, J.: Wertorientierte Unternehmensführung: Theoretische Konzepte und empirische Befunde. Dt. Univ.-Verl., Wiesbaden (2003)

11. Garrison, R.H., Noreen, E.W., Brewer, P.C.: Managerial Accounting, 11th edn. McGraw-Hill/Irwin, Boston (2006)

12. Ehrbar, A., Mühlfenzl, I.: EVA, Economic Value Added: Der Schlüssel zur wertsteigernden Unternehmensführung. Gabler, Wiesbaden (1999)

13. Kames, C.: Unternehmensbewertung durch Finanzanalysten als Ausgangspunkt eines Value Based Measurement. Lang, Frankfurt am Main (2000)

14. Lambert, D.M., Burduroglu, R.: Measuring and selling the value of logistics. Int. J. Log. Man. 11(1), 1-17 (2000) 